\title{
THE BRITISH
}

\section{JOURNAL OF DERMATOLOGY.}

\author{
SEPTEM B R , 1902 .
}

\section{NOTE ON A SPECIMEN OF TINEA MICROSPORON OF THE CAT.}

By LESLIE ROBERTS, M.D.,

\section{Hon. Dermatologist to the Liverpool Royal Infirmary.}

IT is often characteristic of this variety of Trichophyton* that it can adhere to and develop freely on a comparatively wide range of hosts. The first hosts, in the present case, were two kittens that lived in a certain town in Lower Egypt. When quite young their bodies were observed to be a "little scurfy." For convenience of description we will name them A. and B. Of B. all I can report is hearsay; that it was sent to a family in Ramleh, where several of the children soon after developed "spots" on the body. A. left Egypt, and after twenty days reached a house in Cheshire, where it was introduced into a large family of children. The gentleman who was responsible for A. during the journey to England is said to have noticed a ringworm-like patch on some part of his body, which developed while the cat was under his care. A. had not been many days in the family before a red plaque on the neck was observed on the eldest daughter. Within a week from this six of the children appeared with similar plaques. On the third week I was consulted, and explained to them the nature of the disease. By this time nine of the family were affected, and also a grey English kitten. I saw them, and the two kittens. The diagnosis was confirmed by the

* I use the word Trichophyton advisedly, and in a generic sense, as, in my opinion, rightly covering the microspora and megalospora. 
microscope. From one to two weeks later the three youngest children showed patches of ringworm on the scalp. as well as on the smooth parts of the body. At this time the affection spread to a neighbouring house, where a child and a Skye terrier were infected. I saw them and confirmed the diagnosis. The source of their contagion was the grey English kitten. It has since been reported to me that the father, mother and an aunt have shown signs of the disease on the body. The following scheme represents the extent of the contagion as known to me at present :-

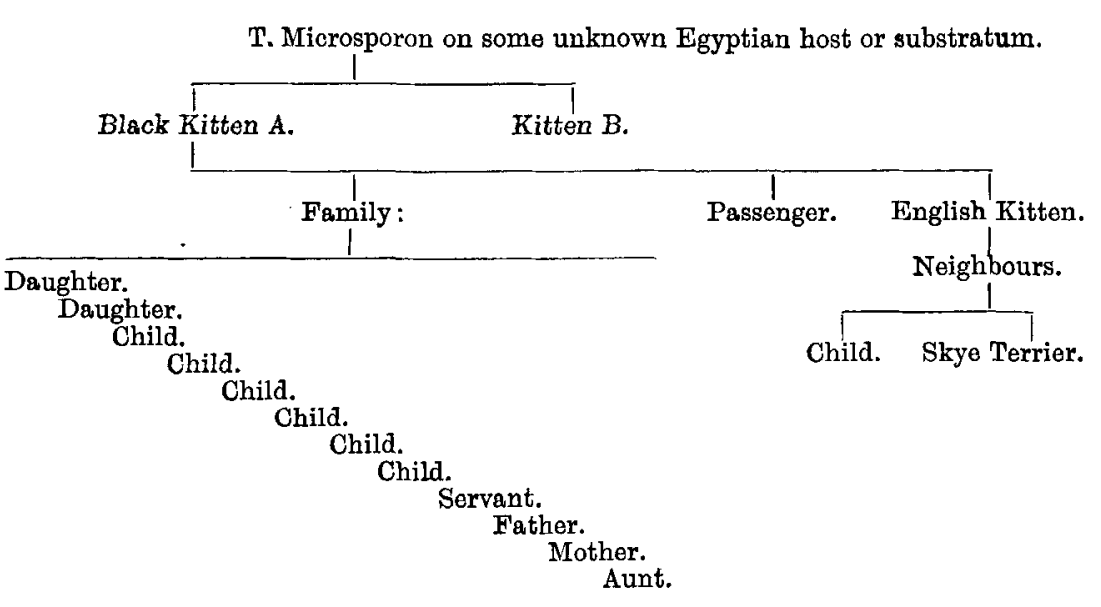

\section{Cinnical and Mrcroscopic description of Tinea Microsporon in the • THREE HOSTS.}

1. The CAts.-(i.) Clinical.-The disease, which was limited to the forehead and ears, was characterised by the formation of bald patches presenting a desquamating surface, and numerous short, broken hairs which could be easily extracted. There was no change of colour and no discharge, so that the disease could be very easily overlooked-as, indeed, was the case when the veterinary surgeon, who was first consulted, examined the animal. There was no essential difference between the Egyptian and English kittens in respect of the clinical aspects of the disease, only it was a little more conspicuous in the latter, owing to its fairer complexion.

Microscopical examination of the fungus in situ.-The fungus was observed in the hair as well as in the scales, but the quantity in the 
former was very much smaller than that found in human hair. The vegetation appeared to be both internal and external to the hair shaft, but chiefly external, and its growth had been followed by the partial destruction of the hair. The mycelium occurred in both vegetative and fructifying forms, the latter having the aspect of closely septated hyphæ.

2. The Doa.-(i.) Clinical.-The Skye terrier in question was brought into the infected house by a neighbour's child, and the kittens were made to ride on its back. There can be no doubt, therefore, as to the source of contagion. The disease, when I saw the dog, was indicated by a single circular patch, which had a perceptible amount of infiltration at the margin, so that to the finger, more than to the eye, it conveyed the sensation of a firm raised ring. It was also slightly hyperæmic, so as to appear of a light red colour. Many of the hair-shafts within the ring were broken about one or two lines above the surface of the body. The cuticle of the epidermis was slightly desquamating. On the whole the clinical aspect of the ringworm in the dog was very different from that of the kitten s.

(ii.) Microscopical.-As in cats, so here also I observed that the larger vegetation was in the epidermis, and not in the hair. The mycelium was in the two conditions of vegetation and fructification. The sporulation was by segmentation, the septa being near together, giving the hyph the aspect of rows of square or round-shaped beads strung together.

3. The Chimbren.-(i.) Clinical.-The children had numerous red scaly patches, most of which were situated on the neck. In aspect they resembled ordinary tinea circinata, the hyperæmia being well marked, fading in the central parts of the patches and pronounced at the margins. Desquamation was evident, and the exfoliating scales were detached at one end while still adherent at the other, as is usual in tinea circinata. There was no vesication. In the three youngest children the scalp was affected as well as the smooth parts. The earliest indications of invasion of the scalp was a minute circular eaten-out hole in the cuticle surrounded by a free collar of horny epidermis. In consequence of the thinning of the epithelium, the patch looked of a pink colour. It is doubtful whether there was actual hypermmia. At this stage of attack the hairs and tollicles gave no indication of invasion. A little later the broken 
epidermis formed a tiny heap of scales, just as we see in a child's scalp attacked by trichophyton megalosporon. In the next period of development the hairs showed signs of invasion by breaking off one or two lines above the orifices of the follicles. The follicles themselves did not appear to suffer, at least there was no suppuration and no swelling. Quite a considerable number of hairs in the infected area appeared to have escaped the fungus.

(ii) Microscopical.-(a) Scales.--The mycelium was for the most part simple non-fructifying, 3 to $4 \mu$ in diameter, with septa far apart and branches lateral and terminal. There were no free or adherent gonidia. Sporulation was by segmentation.

(b) Hairs.-The growth of the fungus was many times more abundant than in the hairs of the eat and dog. The cuticle of the shaft was corroded, and the regularity of its contour was consequently lost. Vegetation was both external and internal, but chiefly external. The cortical plates were separated by interstitial air and also by delicate mycelial filaments. The exterior vegetation appeared as closely juxtaposed rows of small spores with highly refractile contents. The resemblance to common microsporon was at once apparent, but careful observation, especially of the less crowded parts, showed that the spores were arranged one behind another in linear series.

In the denser parts of the vegetation this linear arrangement gave way to the impression of a mere crowd of minute spores. In the interior of the hair where more nourishment was to be had the mycelia were non-fructifying, and the septa consequently far apart. No other form of sporulation was to be seen but that of septation of the hyphæ.

\section{The Fungus under Cultivation.}

The fungus was cultivated on only one soil,* namely agar, with 2 per cent. peptone and reared at a warm but variable temperature, the limits being $28^{\circ}$ and $35^{\circ}$. The vegetation forms a flat even membrane without striking colour or odour. The aerial surface is white, but this changes with age, from the centre outwards, into a

* The composition of the soil was as follows:-Agar, 2; beef extract, $\frac{3}{4}$; peptone, 2 ; water, 100. 
pale yellowish brown or buff colour. The surface is not smooth, but appears as if dusted over with a fine sand. The extreme margin is composed of a fringe of pale white delicate threads. The growth is not accompanied by liquefaction of the medium.

I have met with many fungi of more vigorous growth than the present specimen. Still, microsporon of the cat must be described as a fungus of strong powers of vegetation, for in five days at a temperature of $32^{\circ} \mathrm{C}$, , one culture had attained the size of a shilling.

Morphology of the Cultured Fungus.-The most remarkable feature of this fungus when cultivated in such a soil as peptone-agar is the change which occurs in the old mycelium. This consists in the conversion of the terminal portion of the filaments into a brood of megalogonidia, encapsuled by thick walls and divided by septa. These brooding gonidia have been frequently described by botanists, and they are said to be very commonly met with in the mucorini. They were named by Van Tieghem, "chlamydospores," and by De Bary, "Brood Gemmæ." M. Bodin has described and figured structures in the microspora which he regards as chlamydospores. They have been frequently observed and well-described by Colcott Fox and Blaxall. In the specimen of microsporon now under consideration the chlamydospores resembled a boat with blunt pointed ends, the septa corresponding to the seat of the boat (see Fig. 2). They are very numerous in old specimens and bulk largely in the field of the microscope. At the period of their development when I examined them, they averaged in length 30 to $40 \mu$ and 5 to $7 \mu$ in breadth, the septa, varying in number from 3 to 10 , being about 3.5 $\mu$ apart. No prickles or bosses, so often observed in old chlamydospores, had developed at this time, but these and other modifications of the capsules have been described by Colcott Fox and Blaxall. It must be noted that these brooding megalogonidia are never found on young mycelium. Their development begins in tho centre of the vegetating colony, that is on the old filaments which have passed all active growth and have entered the resting period. The thickness of their walls, as De Bary says, shows that they are adapted to a persistent state of rest, and that they are capable of offering resistance to exterior influences. It is a significant fact that these chlamydospores are a common form of reproduction in all the 
animal ringworm fungi, and this would lead us to suspect that these fungi are accustomed to pass dormant periods (if not active also) on some vegetable substratum before passing to the animal host. Until the substratum is found the complete life history of these fungi cannot be written. With regard to what M. Bodin has described and figured as chlamydospores $I$ am not so certain as to their nature. I have cultivated many hundreds of specimens of human microspora and examined a fair proportion of these with the microscope, and I think I hardly ever failed to find these ampulliform swellings in the continuity of the old mycelial filaments. Nothing is commoner than to find these swellings in old and starved mycelia, but $I$ have never seen them subdivided by septa into resting spores. For this reason I cannot share M. Bodin's opinion as to their nature. I am inclined to regard them as food-storing cells.

In my specimens of microsporon no aerial gonidia were to be seen.

\title{
LUPUS ERYTHEMATOSUS: ITS ASSOCIATION WITH HYPER- TROPHIC RHINITIS AND OZझNA, AND ATROPHIC CHANGES OF THE TYMPANUM AND EXT. AUDITORY MEATUS.
}

\author{
BY WILFRID B. WARDE, M.D., M.R.C.P., \\ Assistant Physician to Blackfriars Skin Hospital.
}

Circumstances induced me, a short time back, to investigate the lesions of mucous membranes met with in cases of Lupus erythematosus. I was surprised to find that they were more numerous than I expected, and a careful examination of cases revealed a uniformity of results that could scarcely be accidental.

The number of cases, of which I possessed notes, was fifteen. Unfortunately three of them had disappeared before my attention was directed to the points under consideration. I have thought it better to retain them, however, in order that I might record fifteen consecutive cases, seen between August, 1901, and the present date, August, 1902.

The number is too small to enable one to draw definite conclusions; 